\title{
Serial verbs in modern standard Arabic
}

\author{
Yasir Hameed Alotaibi \\ Associate Professor of Linguistics, Taif University, KSA \\ y.h.alotaibi@tu.edu.sa
}

قبول البحث: 2021/11/18

مراجعة البحث: 10/26/ 2021

استلام البحث: 2021 /9/19

DOI: https://doi.org/10.31559/JALLS2021.3.4.3 


\title{
المجلة الدولية للدراسات اللغوية والأدبية العربية
}

International Journal for Arabic Linguistics and Literature Studies (JALLS)

\section{Serial verbs in modern standard Arabic}

\author{
Yasir Hameed Alotaibi \\ Associate Professor of Linguistics, Taif University, KSA \\ y.h.alotaibi@tu.edu.sa
}

Received : 19/9/2021 Revised: 26/10/2021 Accepted : 18/11/2021 DOI : https://doi.org/10.31559/JALLS2021.3.4.3

\begin{abstract}
This paper aims to discuss serial verb constructions in Modern Standard Arabic (MSA). It argues against the claim that this structure does not exist in MSA. We examined parallel structures in this paper: being verbs and what is called albadal 'apposition' in the traditional grammar of the Arabic language. This paper argues that the first structure should be analyzed as an auxiliary structure that contains two clauses, while the second structure should be analyzed as a serial verb structure as it denotes, among others, a complex situation, shares the same subject, and contains one clause. Finally, this paper provides a brief syntactic analysis for being verbs and serial verbs in MSA within the lexical functional grammar (LFG) framework, showing the differences between the two structures.
\end{abstract}

Keywords: serial verbs; being verbs; complex predicate.

\section{Introduction}

Serial verb construction is a structure that contains two or more verbs as long as none of them is an auxiliary occurring in a single clause. In the literature, there is a debate about what structures should be analyzed as serial verbs. Linguists may agree on some features of serial verbs: they contain more than one verb, form a complex predicate, and occur in a single clause. There is, however, a debate about other features, such as whether the verbs share some or all arguments. Additionally, there is a disagreement about whether structures in some languages serial verbs or other constructions are.

In this paper, we will focus on some characteristics of serial verbs that satisfy most linguists. We suggest that serial verbs should possess the following properties:

1. Two or more independent verbs are contained, and none of them is an auxiliary.

2. The verbs occur in one clause.

3. The verbs form a complex semantic meaning.

4. There are not overt or covert conjunctions, meaning that it is not a coordinate structure.

5. There are no markers of subordinations.

6. A serial verb construction should contain one tense and one aspect.

7. The verbs share at least one argument, which is usually the subject.

The previous characteristics show that coordinate structures, auxiliaries, and subordinations are not serial verbs. Coordinate structures are completely different from serial verbs, but they usually overlap with serial verbs because, in many languages, conjunctions may be deleted. This leaves verbs without boundaries, which makes them similar to serial verbs. This will be clear in our discussion of serial verbs in modern standard Arabic (MSA) throughout the paper. Baker (1985) states that some authors mix serial verb constructions and coordinate structures that do not contain conjunctions. Therefore, it is important to have criteria that identify serial verb constructions and separate them from coordinate structures that have covert conjunctions. The closest structure to serial verbs is the auxiliary structure because it contains two verbs and it may be analyzed as occurring in a single clause, as we will see later. However, in the previous properties of serial verbs, we stated that both verbs should form a complex meaning; this indicates that each verb has its own semantic meaning, and the meaning of the whole structure is contributed by all verbs. Auxiliaries, meanwhile, do not have any semantic content. As for subordinations, they are different from serial verbs because this structure contains a main clause and a subordinate clause; that is, the verbs do not occur in one single clause. In some languages, such as Loniu and Paamese, the boundary between main clauses and subordinate 
clauses may be lost.

The remainder of the paper is divided into four sections. Section 2 discusses the main properties in serial verbs and shows some tests for real serial verbs. In this section, we discuss how this structure contains verbs that occur in a single clause, express a complex event, indicate the same tense and aspect, and share one argument. Through tests, we demonstrate that verbs occur in one single clause, such as negation, pronouns, and their antecedents and filler-gap. We use some examples of coordination, subordinations, and auxiliaries in MSA to show that these structures are different from real serial verbs. Section 3 shows two structures in MSA that are similar to serial verbs. The first structure is being verbs and they are divided into two groups: the first contains verbs that have no semantic content and should be analyzed as auxiliaries while the second includes verbs that have some kind of semantic meaning. Based on some evidence, we argue that the latter should also be analyzed as auxiliaries but suggest that they have two clauses. The second structure is what is called albadal 'apposition'in traditional grammar. We argue that this structure should be analyzed as serial verbs as long as the two verbs constitute a complex meaning. This argument is important because there is consensus in the literature that MSA has no serial verbs (see Altakhaineh and Zibin (2018)). Section 4 provides a brief syntactic analysis for being verbs that contains two clauses and serial verbs in MSA, showing the syntactic differences between the two structures. The final section is a conclusion.

\section{An overview of Serial verbs}

The term 'serial verbs' was first used by Stewart (1963) to describe a structure in Akan, which is spoken in WestAfrica. The term was then used for similar structures in a close language, such as Sranna by Sebba (1987). Other researchers used this term for similar languages in Asia and Africa (see Lord (1993) and Bisang (1992)). There are several definitions in the literature for serial verbs. Larson (1991) defines serial verbs as constructions that contain a subject followed by more than one verb or verb phrase, which usually agree with this subject. In Collins (1997), serial verbs are verbs that share the same subject and tense and that are not separated by a marker of subordination or coordination. These are not the only definitions for serial verbs, but the primary agreement in all definitions is that this construction contains more than one verb and that these verbs occur as a unit and constitute a complex event (see Sebba (1987) and Aikhenvald et al. (2006)). Based on the definitions of serial verbs, serial verbs may be extended to cover many structures in different languages (see Van Staden et al. (2008) and Foley (2010)), and this causes a debate in the literature about which structures should be analyzed as serialverbs.

For the purposes of our paper, we will describe the serial verb structure based on the main features found in the literature. There are several primary properties of serial verbs; first, we will discuss those related to the semantic meaning of this structure, followed by a discussion of the properties that differentiate serial verbs from similar structures, such as auxiliaries, coordination, and subordinations.

The serial verb construction contains two or more verbs functioning together to express a complex event, meaning that each verb should contribute to the whole meaning in the construction and the result is a sequence of related actions that make a single event. This complexity may be denoted by adding different arguments that function as objects of these verbs (see Hyman (1975) and Sebba (1987). Durie (1997) states that the serialized verbs in this construction, in order to be grammatical, must be interpreted as indicating a single, coherent event. However, languages have different restrictions that allow specific combinations of verbs to be serialized in a serial verb construction. These restrictions are influenced by cultural factors. For example, in Hmong culture, the verb "play" and the verb "dance" always appear together and therefore can be serialized in a serial verb construction and viewed as a single event. In contrast, in Hmong culture, the verb "listen" andthe verb "dance" are viewed as separate events and therefore cannot be combined together in a serial verb construction. Similarly, a language like Alamblak allows a special combination of verbs to constitute a single event in serial verbs constructions depending on some pragmatic and cultural factors. For instance, climbing a tree and looking for insects is normal in this culture, and therefore the verbs "climb" and "look" can be serialized. In contrast, speakers in this culture reject a combination like climbing a tree to see the stars, meaning that the verb "climb" cannot be serialized with the verb "see" (see Bruce (1988)).

Additionally, it is common in serial verbs to express the direction of motion or the result of an action (see Byrne (1987) and Schiller (1990)). Additionally, serial verbs may be used to express some specific aspects, such as the completive aspect, movements, manner, purpose, or causation (see Stahlke (1970) and Seuren (1990)). Some combinations of verbs in this structure may express an idiomatic meaning (see Schachter (1974)).

As motioned above, linguists have different opinions about serial verbs that lead to differences 
among their analyses of the structure. In the following paragraphs, we will discuss somesyntactic features that may assist in determining the structure of real serial verbs. As these features may differ from one language to another, the issue becomes more complicated.

First, the most important feature of serial verbs is that they occur in one single clause, meaning that there is no grammatical or intonational boundary between verbs. This requires the coordinate structure and also structures that contain subordinate clauses to not be serial verbs. The following examples are not serial verbs, even though each example contains more than one verb. In example (1a), the main clause is the one that contains the verb admire, which requires a complement and therefore forms a separate clause. Similarly, example (1b) contains two verbs that occur in two separate clauses in the coordinate structure.

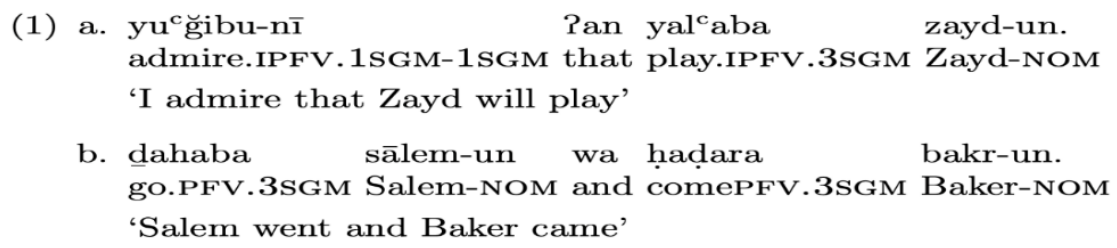

However, the auxiliary structure is more similar to serial verb constructions than the previous structures. This is because auxiliaries may be analyzed as containing one clause. In transformational grammar, there are two approaches for analyzing auxiliaries, namely, verb analysis and separate analysis. In the former, the auxiliary is analyzed as a verb; this entails that the auxiliary requires a subject and a complement, which contains the lexical verb. In this approach, therefore, there are two clauses. In the latter, the auxiliary is analyzed as a helping verb, meaning that the structure contains one clause (see Chomsky (1955)). However, this structure is different from serial verb structures in that it contains one verb, the lexical verb, while the auxiliary is not analyzed as a verb in this approach. The same two approaches are found in a non-transformational theory like the Lexical Functional Grammar (LFG) theory, which has two analyses for auxiliaries: the aux-predicate analysis and the auxfeature analysis. In the former, the auxiliary is analyzed as a verb that requires a subject and a complement, meaning that there are two clauses in this analysis. In contrast, in the aux-feature analysis, the auxiliary is analyzed as a feature. There is therefore one clause in the analysis and it contains one verb (see Falk $(1984,2008)$ and Alotaibi (2017)). The following f-structure in (2b) shows the aux-feature analysis for the example in (2a). Here, the auxiliary in the f-structure is represented as a feature, which is TENSE PAST. There is one verb that makes the auxiliaries in this analysis different from serial verb constructions.

(2) a. Mary was eating chicken.

$$
\text { b. }\left[\begin{array}{lll}
\text { PRED } & \text { 'EAT }\langle\text { SUBJ, OBJ }\rangle \\
\text { TENSE } & \text { PAST } & \\
\text { SUBJ } & \text { [PRED } & \text { 'MARY'] } \\
\text { OBJ } & \text { [PRED } & \text { 'CHICKEN'] }
\end{array}\right]
$$

Second, verbs in this construction should express a complex situation, meaning that all verbs in a serial verb construction should express a single situation. This is different from the coordinate or subordinate structure, where verbs express distinct situations. For example, the previous examples of subordination and coordinate structure in (1), repeated as (3) below, are different from serial verbs in that each verb in the structure expresses a separate event. In example (3), the main verb admire expresses one meaning that is separate from play, the verb in the subordinate clause. In the same way, the two verbs go and come in the coordinate structure in (3b) express two different events. 
(3)

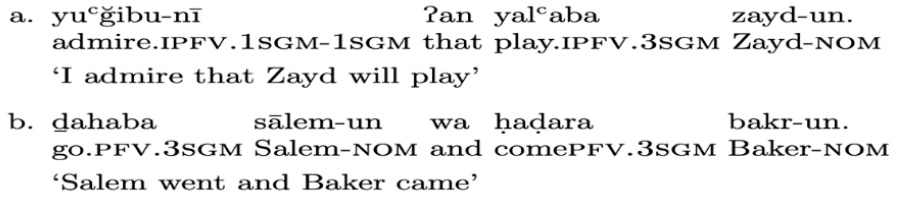

The closest construction to serial verbs in this regard is an auxiliary because the auxiliary and the lexical verb in this structure express one single event, but we may say that this event is not complex in the same way as in a serial verb structure. Generally, it is assumed that the auxiliary expresses the tense and the lexical verb expresses the situation with the aspect. In MSA, kān, which should be an auxiliary, may precede a lexical verb, as shown in (4). In this example, the auxiliary precedes a lexical verb, and the result is one single situation, but with a specialaspect.

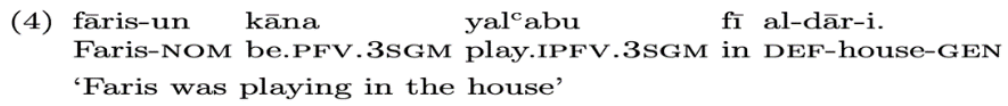

Third, because the verbs in serial verb constructions occur in one single clause, this construction requires one tense and one aspect. In some languages, such as Sranan, one verb carries the tense or the aspect marker; in Akan, both carry the same marker of tense or aspect (see Schachter (1974)). In Akan, the double tense markers may be obligatory in some structures of serial verbs. In Saramaccan and a few other languages, there are two options: namely, it is possible that all verbs in serial verb constructions are marked for tense, or only one of them is marked for tense, as stated by Byrne (1990). Again, this property differentiates serial verb structures from coordinate structures or subordinations, where it is possible for each verb to have its own tense or aspect. In coordinate structures in Arabic, as well as other languages, it is possible that each verb indicates a different tense and aspect. In the following example in (5a), the first conjunct contains a verb indicating the past time reference and the second conjunct contains a verb with a present time reference. Similarly, the tense and aspect of the main clause may differ from the tense and aspect of the subordinate clause. For example, in the previous example in (3a), repeated as (5b), the time reference of the subordinate clause is in the future and comes from the complementizer. This means that the imperfective verb in this clause is infinitive, while the time reference of the main clause is the present and the tense comes from the imperfective verb. Again, the closest construction to serial verbs is the auxiliary structure because it has one tense even though the form of auxiliary and the lexical verb may be different, as in example (4).

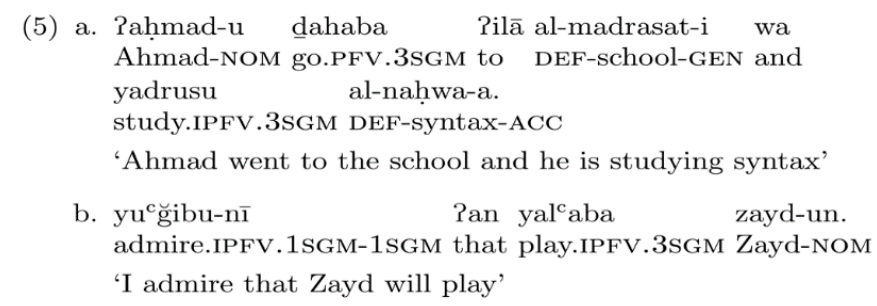

Fourth, because verbs in this structure are in one clause, we should be able to negate the whole clause or assert the truth of it by using one negative particle. This means that we cannot negate one verb in this structure and assert the other at the same time. However, languages handle negation differently; some languages, such as Sranan, use one negative particle to negate the clause of serial verbs, while other languages, such as Ewe, that use verbal affixes should separately negate each verb in this construction. In other structures, such as subordination or coordination, we can negate verbs separately. In the following coordinate structure, the first conjunct is negated in (6a) and the second is negated in (6b). The case in subordinate structures and auxiliary structures is the same. 


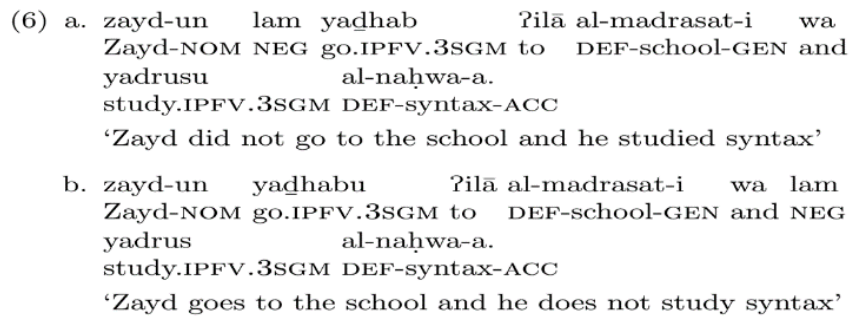

Fifth, a pronoun in a serial verb construction cannot refer to an argument in the same construction. In other words, a pronoun cannot take an argument in the same serial verb construction as its antecedent. This is because they are at the same clause, and it is impossible for the pronoun and its antecedent to occur in one clause. This differs in coordinate structures or subordinations. The coordinate structure in (7a) contains a pronoun in the second conjunct and its antecedent is the object of the verb in the first conjunct. Similarly, the subordinate clause in (7b) contains a pronoun and its antecedent is the object of the verb in the main clause. Auxiliary structures are different from coordination and subordination, however, in that the pronoun and its antecedent cannot occur together in a sentence that contains an auxiliary followed by a lexical verb. We will return to auxiliaries again in this paper.

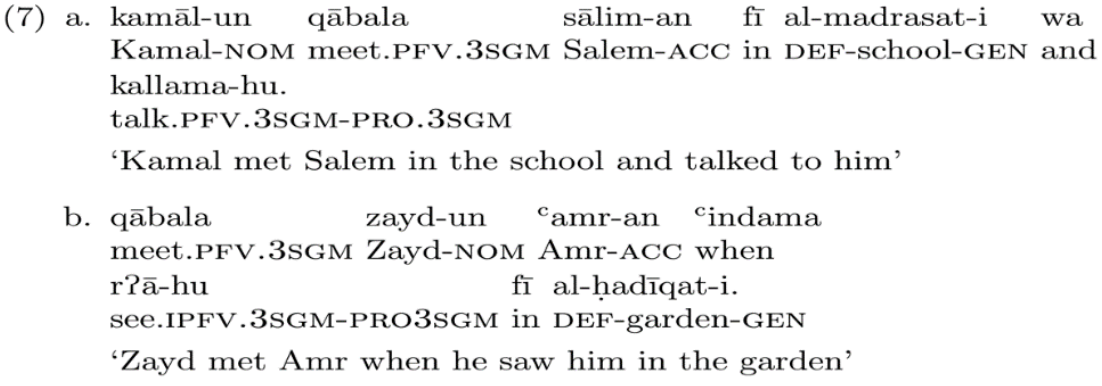

Sebba (1987) argues that in Sranan, serial verb constructions do not contain a pronoun with its antecedent in the same clause; if this happens in similar structures, that must be a special kind of coordinate structure that does not contain conjunctions. In this type of coordinate structure, verbs should describe separate events and a pause may separate them.

Sixth, an important test that can distinguish serial verb constructions from coordinate structures is the filler-gap construction in relative clauses and wh-questions. Ross $(1967,1986)$ states that, in English, there are some types of constructions that cannot contain a gap without its filler. The coordinate structure is one of these constructions, which he called islands. For example, the example in (8a) contains a coordinate structure in English. The first conjunct has a transitive verb with an object and the second conjunct is the same. In this structure, we cannot extract any object in the coordinate structure and therefore the two examples in (8b) and (8c) are not grammatical.

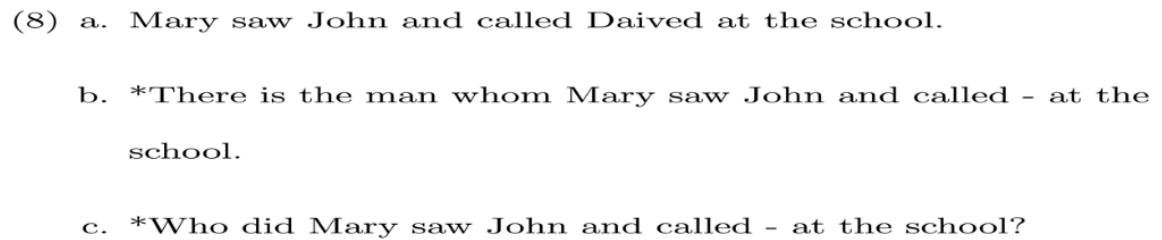

The filler-gap test makes serial verb constructions different from coordinate structures because we can extract both objects in serial verbs. Sebba (1987) uses this test to distinguish between serial verb constructions and unmarked coordinate structures in the Sranan language and finds that if the structure is a coordinate structure without a conjunction, it resists a gap in relative clauses and Wh-questions.

Coordinate structures in Arabic are different in that we can extract the object of the first verb if it is transitive in the wh-question structure and the second verb resists gaping when the object is different from the object of the first verb. This means that we can extract the object of both verbs if they have the same object. In example (9a), the object of both verbs is extracted in the coordinate. 
Structure and sentence are grammatical, while the example (9b) is not grammatical because only the object of the second verb is extracted. This means that the filler-gap test is different from one language to another. Weargue that we can use this test in MSA as well to distinguish between coordinate structures and serial verbs because, as we will show later, serial verb constructions behave differently in MSA.

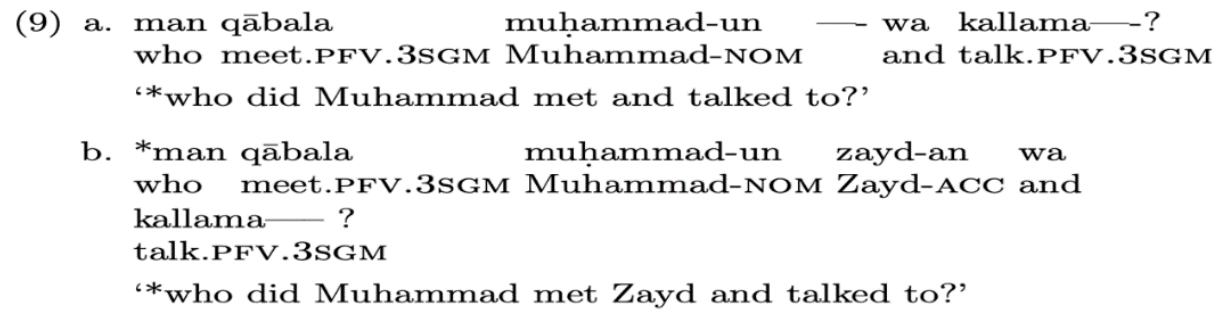

Seventh, all the verbs that occur in serial verb constructions must share one grammatical subject. If the verbs in this structure show subject agreement, they must agree with one subject, meaning that the agreement features must be identical in all these verbs. In some languages, such as Akan, even if the subject is not a semantic argument of one verb, this verb must show agreement with the subject (see Schachter (1974)). This shows that the grammatical relation between verbs and their subject in this structure is independent of semantic roles that are required by verbs. It is obvious that in coordinate structures each verb can have its own subject, but there is a difference between the coordinate structure that coordinates verbs and the coordinate structure that coordinates sentences; in the latter, each sentence has its own subject. Similarly, verbs in subordinate structures may have different subjects in Arabic as well as other languages. In contrast, in the auxiliary structure, both the auxiliary and the lexical verb agree with the same subject; in Arabic, there is a clear morphological agreement. The following example shows this:

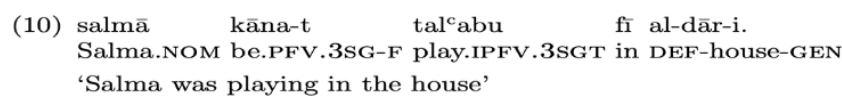

\section{Serial Verbs in MSA}

In MSA, there are some structures that are close to serial verb constructions in that they contain more than one verb. However, some of these structures are different from serial verbs. For example, in coordinate structures, as we saw above, conjunctions indicate that there is more than one clause, and in subordinations, there is a clear boundary between the main clause, and the subordinate clause. In this section, we will examine two structures that we believe are close to serial verbs in MSA. The first structure is being verbs or kān and its sisters; the second is called albadal 'apposition'in traditional Arabic grammar.

\section{1 being verbs:}

Being verbs or kān and its sisters are verbs that can precede lexical verbs (for more information about this type of verb see Ryding (2005) and Alotaibi (2017)), which is why they are similar to serial verbs. We can divide these types of verbs into two groups: the first contains verbs that provide tense or aspectual meaning, and the second includes verbs that contain some kind of semantic content. The first group includes verbs like kān, as shown in (11a), and zall, as shown in (11b). Both have no semantic content, and we argue that they do not make a complex meaning with the lexical verbs that follow them. Therefore, they should be analyzed as auxiliaries rather than serial verbs. 


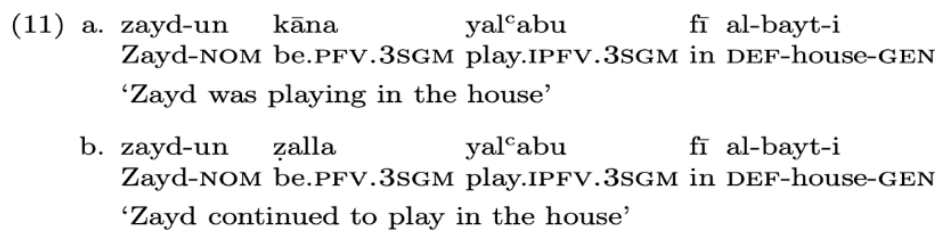

The second group contains verbs that have semantic content and are therefore closer to serial verbs. The difference in meaning between this group and the previous group is that they denote a specific time for the occurrence of an event. We will take two examples of this type of verb, namely, ؟asbah and ؟amsā The first indicates that the situation occurs in the morning while the second indicates that the situation occurs in the evening. The following examples illustrate both verbs:

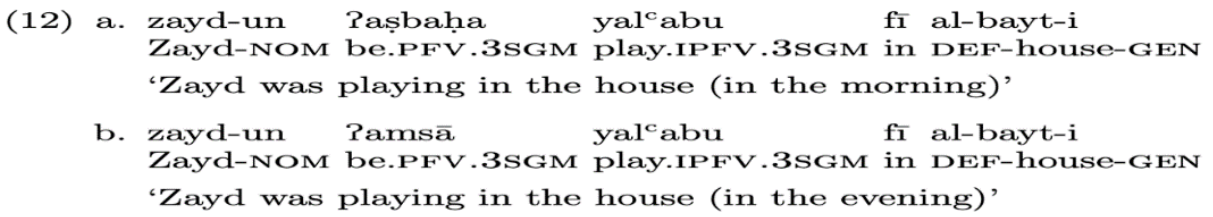

We may accept that both verbs constitute a complex meaning with lexical verbs, but we argue that they should not be analyzed as serial verbs for several reasons: first, this structure is similar to an auxiliary in that the first verb provides the tense while the second provides the aspect. Both examples in (12) have the past tense because the first verb in both examples is in the perfective form, while the second verb, which is in the imperfective form, is infinitive. We argue that this makes this structure different from serial verbs in MSA, which will be discussed in the next section.

Second, we are following Alotaibi (2017) in arguing that this structure contains two clauses. The main argument in support of this claim comes from how each verb in the structure can be negated separately and how the meaning is different. In (13a), the negative particle precedes the first verb, and the scope of negation does not include the second verb, meaning that Zayd did play, but not in the morning. In contrast, the meaning of example (13b) is that Zayd is not playing.

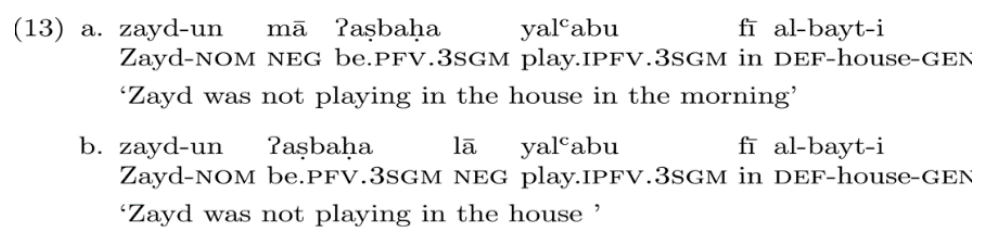

In this section, we maintain that this kind of verb should be analyzed as an auxiliary even though it denotes a specific time. Additionally, we suggest that this construction contains two clauses, meaning that these verbs should be analyzed as predicates, as suggested in Alotaibi (2017). We will return to the analysis of auxiliaries at the end of this paper.

\section{2 apposition of verbs:}

In terms of grammar, apposition 'albadal'denotes a structure that contains two consecutive noun phrases, wherein one noun phrase identifies the other (the second noun phrase is called the appositive). The appositive can be removed without making the sentence ungrammatical. The following examples illustrate this structure in the English language, in which the appositive is initalics: 


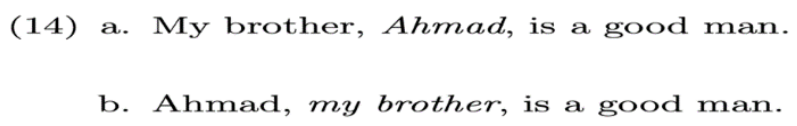

This construction is possible in MSA and in other languages, but Arab grammarians extend this structure to other types of words (see Alandalusi (ND) and Sibawayh (ND)). They argue that verbs can be in apposition. In this paper, we concern ourselves with this construction, where two or more verbs occur together. The following examples illustrate this structure in MSA:

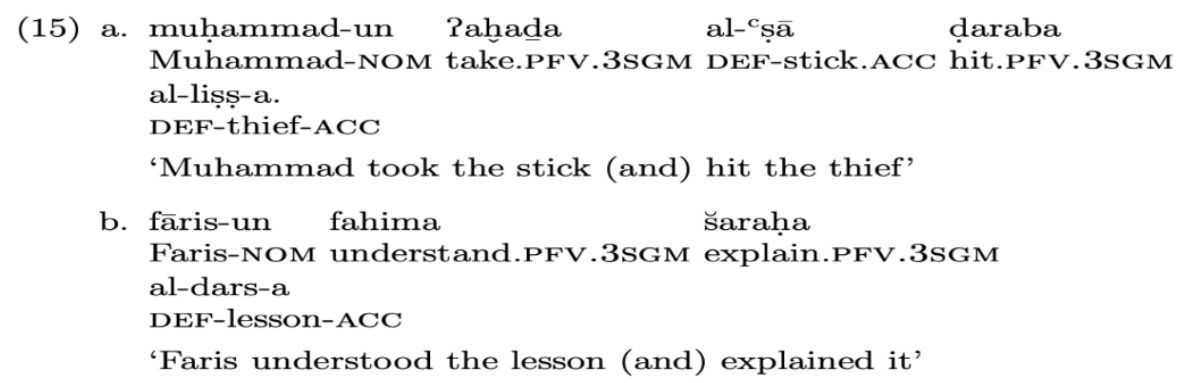

We propose that there are two possible analyses for this kind of structure in MSA: the first is serial verbs and the second is a coordinate structure without a conjunction. We believe that both analyses are possible in this construction and suggest that when the two verbs can constitute a single and complex event, the structure should be analyzed as a serial verb construction. We believe that both examples in (15) are serial verb constructions. In contrast, some examples of this construction, where both verbs express two separate events, should be analyzed as coordinate structures without a conjunction. We will return to some examples of this structure below.

One argument in support of analyzing the examples in (15) as serial verbs comes from traditional grammarians: This structure should have one tense (see Alandalusi (ND)), meaning that both verbs should indicate the same tense. The following examples are not grammatical because the first verb is in the perfective form indicating the past tense, while the second verb is in the imperfective form indicating the present tense:

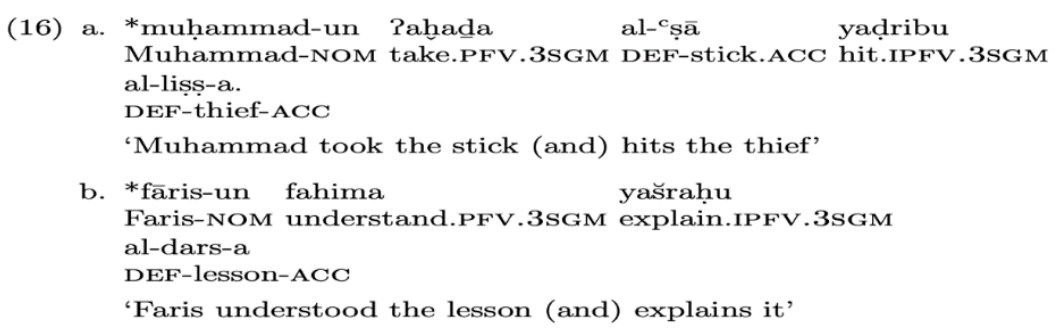

Interestingly, this difference between verb forms is possible in coordinate structures in MSA and the same examples in (16) are grammatical with a conjunction between the two verbs, as shown below in (17). The only change made is in the second example by putting the object of the first verb after it and using a pronoun for the second verb, because each verb in the coordinate sentence bears an object function.

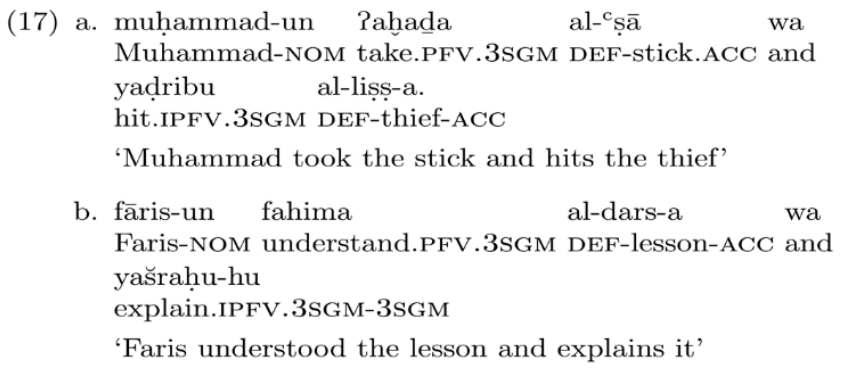

We believe that this is strong evidence that the structure in the examples in (15) illustrates serial 
verbs in MSA. However, a problem arises when the same construction contains two verbs that cannot constitute a single complex event, as shown below in (18):

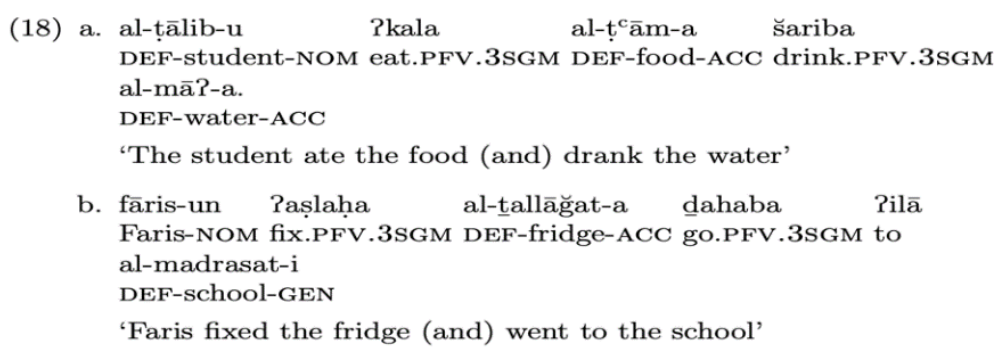

In both the above examples, the two verbs do not form a complex event because each verb expresses a different meaning. In example (18a), the first verb ate cannot be mixed with the verb drank to constitute a complex meaning. The only possible analysis for this kind of structure is that it is a coordinate structure without a conjunction; however, this structure is different from coordination in MSA where it is impossible to accommodate two different verb forms. This means that the following examples are not grammatical. We believe that the only solution here is to propose this structure as a special type of coordination because the conjunction is deleted, bringing the two clauses closer to each other.

(19)

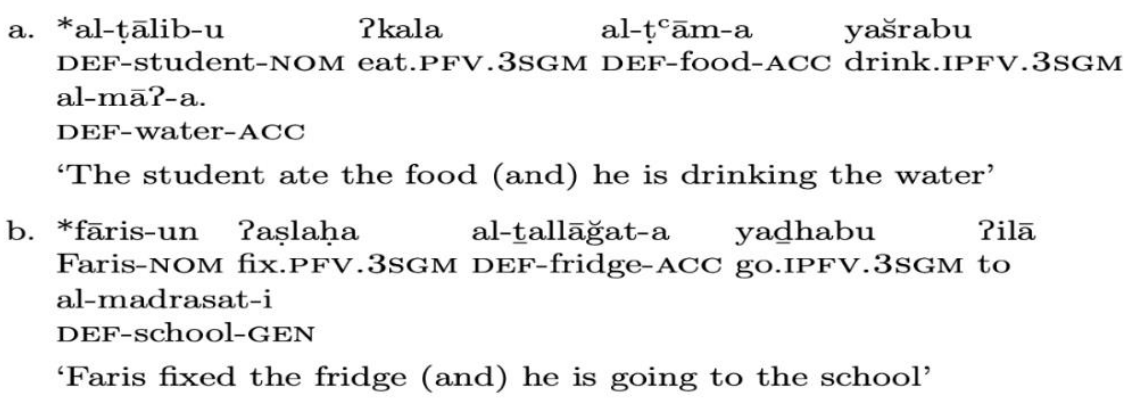

Besides tense, this construction must contain one aspect. In MSA, the imperfective form may indicate two aspects, namely, habitual present and present continuous. If we use two imperfective verbs in this structure, they should have the same interpretation, meaning that both may be habitual or continuous. The perfective form of verbs in the previous examples in (15) can be changed to the imperfective. In this case, both verbs must be in the imperfective, as mentioned before, and both verbs must indicate the same aspect. The following examples in (20) contain verbs in the imperfective form, in which the example (20a) includes the adverb kulla yawm 'every day', which is related to the habitual aspect. In this case, both verbs should indicate habitual aspect. In contrast, two different kinds of adverbs are used with each verb in example (20b), in which the first indicates the continuous aspect and the second the habitual aspect. The result is that the sentence is ungrammatical, as shown below:

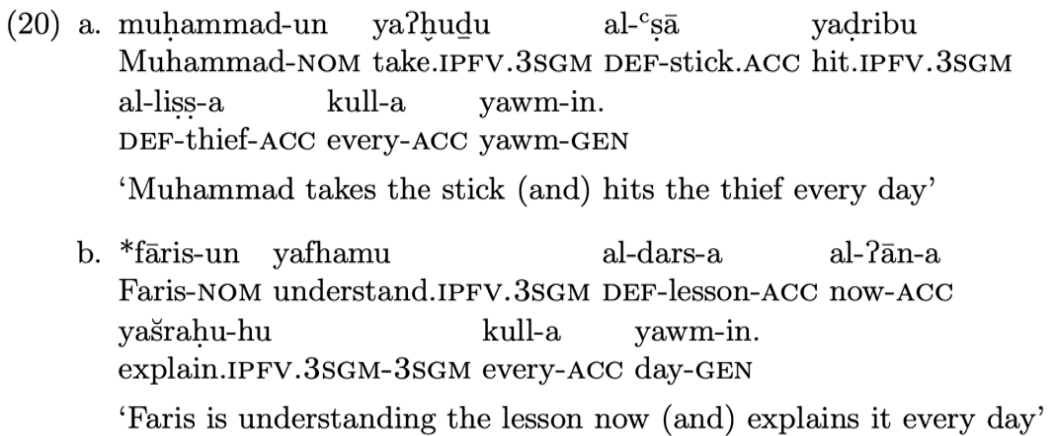

Another argument in support of analyzing the structure in (15) as a serial verb construction comes from how the verbs in this structure occur in one single clause, meaning that there is no grammatical boundary or any kind of intonation that indicates more than one clause. Additionally, this 
structure contains one tense and one aspect, and this fact shows that there is only one clause. In this structure, the tense and aspect of the sentence are unified, but each verb carries the same marker of tense or aspect, as shown in the previous examples. In section 2 , we mentioned that languages have different ways of showing tense and aspect markers on verbs in serial verb constructions; in some languages all verbs carry the same markers of tense and aspect, while in other languages one verb carries the tense and aspect markers of the whole clause. We believe that this diversity comes from the differences in the tense system across languages. In MSA, if more than one verb occurs in the same structure, each verb must be in the perfective or imperfective form, which carry all the morphological information. In this case, the context specifies the tensed or untensed form of verbs.

Moreover, the existence of a single clause shows that we can either negate or assert the truth of the whole clause, which is exactly what happens in this construction in MSA. We can also use one negative particle to negate both verbs in this structure or two negative particles to negate both verbs, but more importantly, both verbs must be negated and asserted in this structure. The following examples illustrate the negation, in which a negative particle precedes both verbs in (21a) and only precedes the first verb in (21b). In both examples, the two verbs are negated.

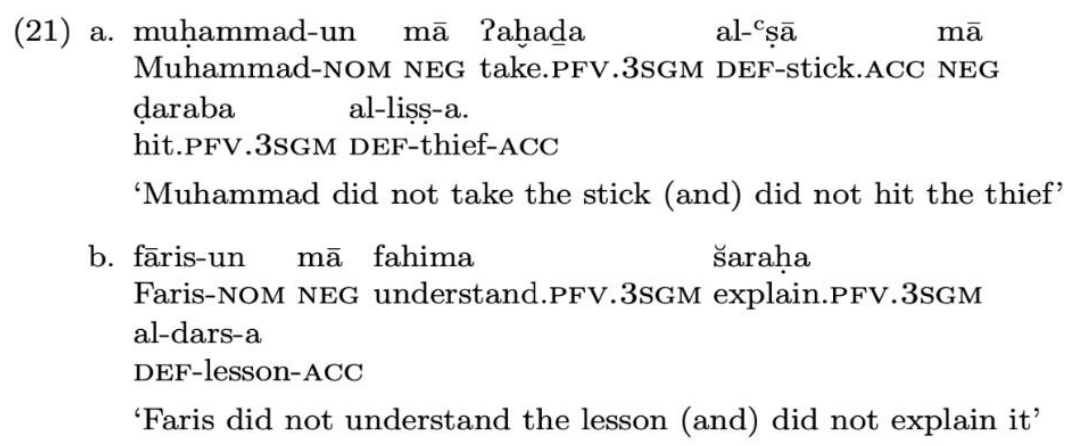

Importantly, coordinate structures are different from the previous examples in that we cannot negate two verbs with one negative particle, and we can negate one verb and assert the other. This supports the statement that our examples of serial verbs are not coordinate structures without a conjunction. The following examples show that each verb in a coordinate structure should be negated separately. In example (22a), one negative particle is used before the first verb, resulting in the first verb being negated and the second verb being asserted; in example (22b), both verbs are negated separately by two negative particles.

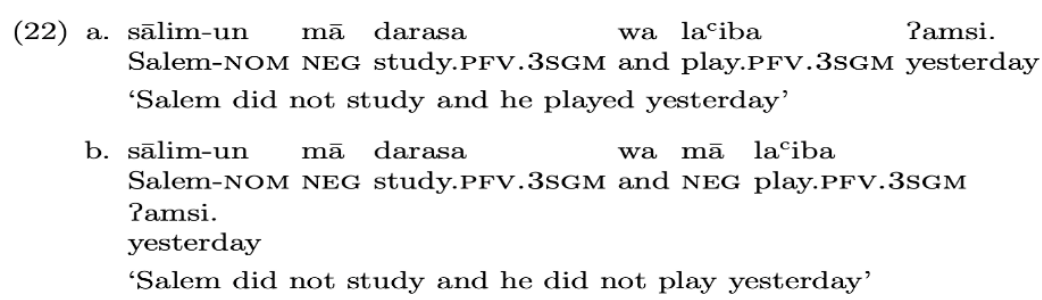

Another argument that supports analyzing this structure as a serial verb comes from how a pronoun and its antecedent cannot occur simultaneously in this construction, implying that the verbs occur in a single clause. This test proves that the verbs have a serial verb structure and that this is not a coordinate structure with a covert conjunction. We previously stated that a pronoun and its antecedent can occur in a coordinate structure, as repeated in the example below:

(23) kmāl-un qābala sālim-an fī al-madrasat-i wa Kmal-NOM meet.PFV.3SGM Salem-ACC in DEF-school-GEN and kallama-hu.

talk.PFV.3SGM-PRO.3SGM

'Kmal met Salem in the school and talked to him' 
In addition, we show in section 2 that the filler-gap test can be used in some languages to distinguish between unmarked coordinate structures and serial verb constructions. For example, in Sranan, unmarked coordinate structures resist gaping and serial verbs allow it. We argue that coordinate structures in MSA behave differently in this test. We state that if the two verbs in a coordinate structure have the same object, this object can be extracted. If they have different objects, the object of the first verb can be extracted. The examples in (9) above, repeated in (24) below, show that the filler-gap test works in coordinate structures in MSA:

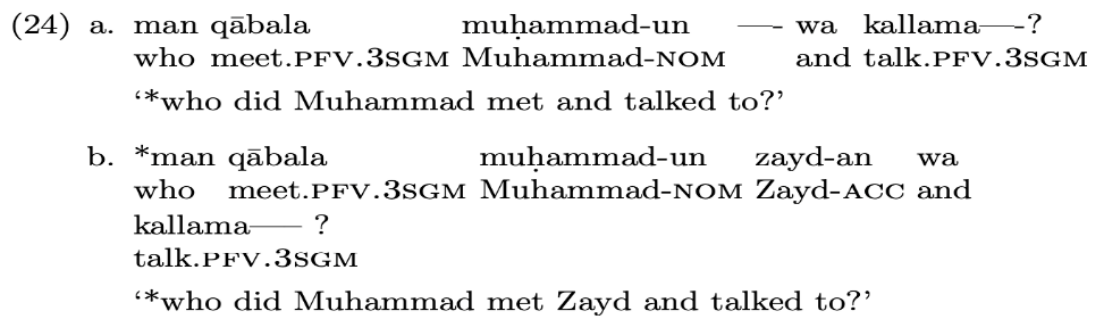

This makes MSA different from Sranan and some other languages, but it does not mean that this test cannot be used in MSA. Serial verbs are different from coordinate structures in MSA in that they resist gaping. This means that, in a serial verb construction, we cannot extract any object. Both examples below are not grammatical because we extract the object of the first verb in (25a) and the shared object in $(25 b)$ :

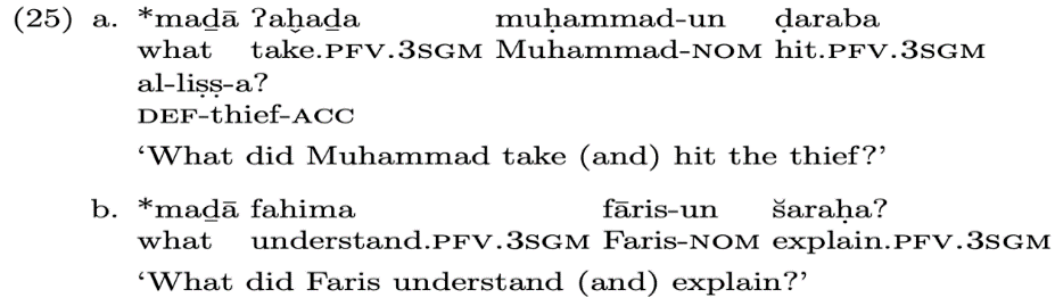

Additional evidence that supports analyzing this structure as a serial verb construction is that serialized verbs in MSA must share at least one argument. The subject in an example like (15a), repeated in (26a), is shared between the two verbs, while each verb has a different object. Additionally, the verbs in example (15b), repeated as (26b), share two arguments: the subject and the object. The fact that each verb can have its own object makes MSA different from some other languages, where verbs in serial verb constructions must share one object. Some researchers, like Stewart (1963) and Baker (1989), argue that serial verbs must share the same object but other re- searchers, such as Crowley (2002) and Aikhenvald (2006), are opposed to this claim and maintain that verbs in a serial verb construction may have different objects.

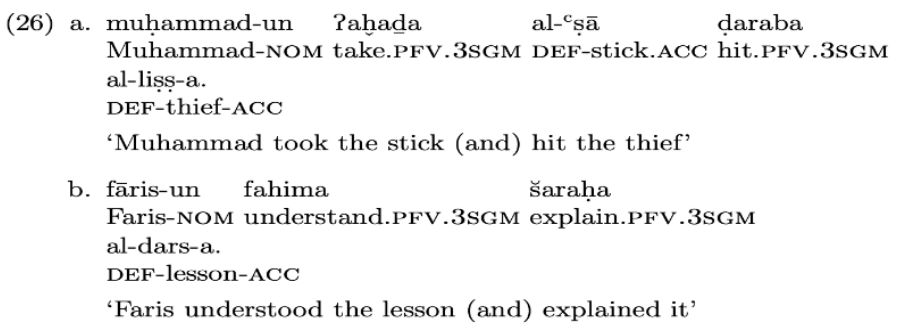

In this paper, we argue that serial verbs in MSA may or may not share the same object, as illustrated above. However, the serialized verbs in the structure must share the same subject or the structure will be a coordinate structure between two sentences. This type of coordination is possible in MSA. The conjunction may be overt, as shown in (27a), or covert, as shown in (27b). 


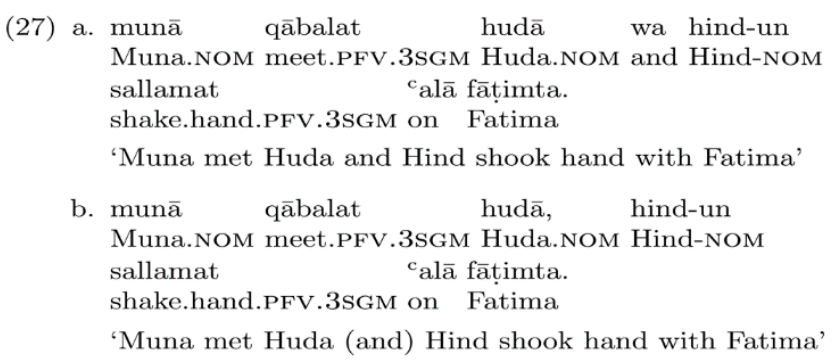

\section{Syntactic Analysis}

In this paper, we have argued that MSA contains two constructions that are similar to serial verbs. The first is some of being verbs that contain a semantic content. Weargue that they are not serial verbs, and they should be analyzed as auxiliaries in spite of their semantic meaning. The second construction is the apposition of verbs and we argue that this construction should be analyzed as a serial verb construction. In this section, we will briefly discuss our suggestions regarding the analysis of both constructions within the LFG framework. We will focus on the functional structure (f-structure) to show the difference between the two structures.

We suggest that the following repeated examples should be analyzed as auxiliaries for two reasons: First, they are similar to auxiliaries in that they indicate tense with lexical verbs that indicate aspect and do not inflect for tense. Second, they contain two clauses; this was supported by the negation test.

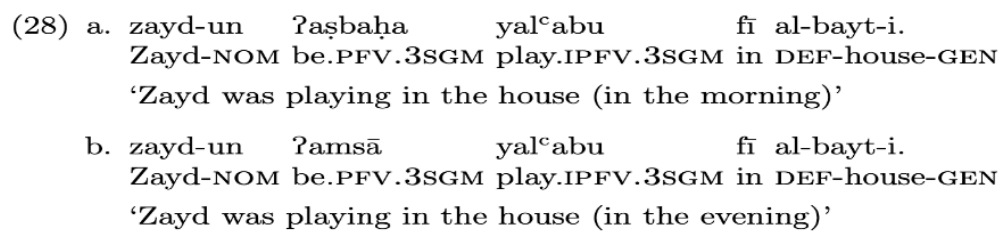

As motioned above, there are two analyses for auxiliaries in LFG: the first analyzes auxiliaries as features and is called aux-feature; the second analyzes them as predicates and is called aux-predicate. In the aux-feature analysis, it is assumed that there is one single clause in which the lexical verb, which follows the auxiliary, is analyzed as the head and the auxiliary is analyzed as a feature indicating the tense. The f-structure in (29) shows the aux-feature analysis, in which the lexical verb playis the head of the clause and occurs in the f-structure as a value for the attribute PRED. The f-structure shows that this predicate requires two functions: SUBJ and OBL. The two functions are represented in two embedded f-structures. Importantly, this f-structure analyzes our example as containing one clause, but we argue that it contains two clauses, and therefore believe that the following analysis, which is the aux-predicate analysis, is correct

(29) $\left[\begin{array}{lll}\text { PRED } & \text { 'PLAY } & \text { SUBJ, OBL }\rangle \\ \text { TENSE } & \text { PAST } & \\ \text { SUBJ } & {[\text { PRED }} & \text { 'ZAYD' }] \\ \text { OBL } & \text { PRED } & \text { 'IN THE HOUSE' }\end{array}\right]$

In contrast, the aux-predicate analyzes an auxiliary structure, as it contains two clauses, in which the auxiliary is the head and takes the lexical verb as a complement. The following $\mathrm{f}$ - structure shows this analysis for the example in (28a). Here, the main predicate is the auxiliary, which requires two functions: SUBJ and XCOMP. The SUBJ requirement is fulfilled by the embedded f-structure that contains the proper noun Zayd, while XCOMP is fulfilled by the embedded f-structure that contains the embedded lexical verb and its requirements. Obviously, the two predicates share the same subject, and the two functions are connected by the number in the square. This analysis, which assumes that the structure contains two clauses, is not appropriate for serial verb construction, as we will see below. 


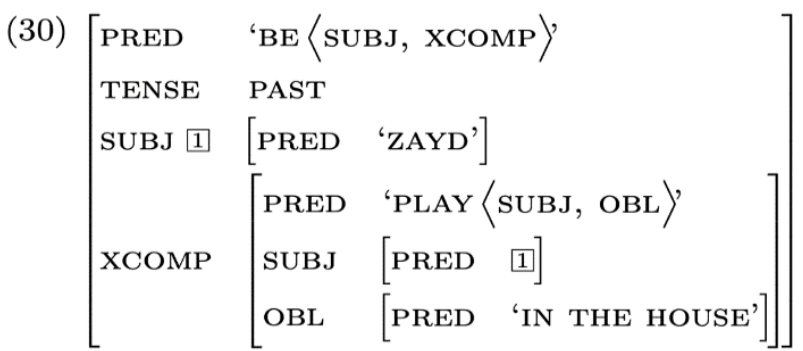

The analysis of serial verbs in the repeated examples below shows that there is one clause that contains two verbs, meaning that there is a difference between this structure and that of the being verbs. The two verbs occur in one clause; they share the same subject but may or may not share the same objects.

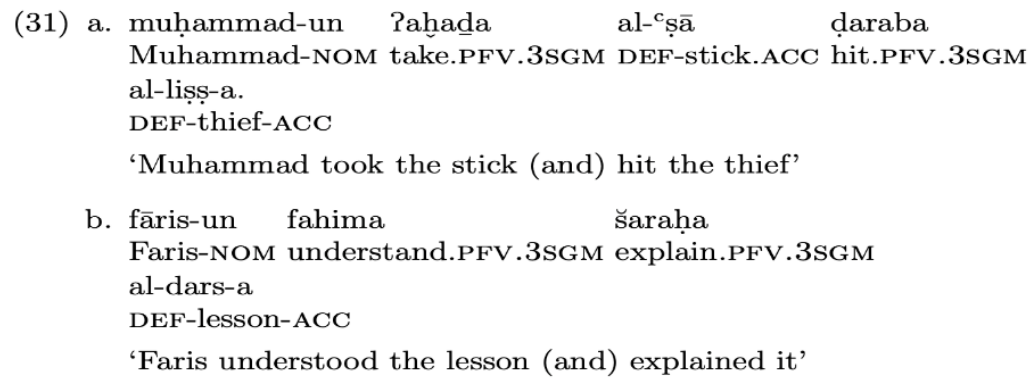

In LFG, a complex predicate that contains more than one verb should be analyzed as one predicate that governs the same grammatical functions (see Bodomo (1996) Butt (1996)). We will start with the second example in (31b) because it is easier. In this example, there are two verbs: understood and explain. If we assume that the second verb has a subject that is controlled by the subject of the first verb, such as in (30), we are analyzing this structure as containing two clauses. Therefore, we should argue that there is one complex predicate, including the two verbs, that bears one subject function and one object function. This analysis is represented in the following f-structure:

(32) $\left[\begin{array}{lll}\text { PRED } & \text { 'UNDERSTAND.EXPLIAN }\langle\text { SUBJ, OBJ }\rangle \\ \text { TENSE } & \text { PAST } \\ \text { SUBJ } & \text { [PRED } & \text { 'FARIS'] } \\ \text { OBJ } & \text { [PRED } & \text { 'THE LESSON'] }\end{array}\right]$

The f-structure in (32) shows the analysis of example (31b). In this analysis, the two verbsare represented as the value of the attribute PRED in the first line of the f-structure. This means that we assume that the two verbs constitute one complex predicate that requires two functions: SUBJ and OBJ. The first function is represented in the embedded f-structure that is the value of the attribute SUBJ, while the second is the value of OBJ. The subject of the complex predicate is therefore Faris, and its object is the lesson.

The example in (31a) is different because each verb has a different object. The object of the verb took is the stick and the object of hit is the thief. In this case, we argue that the same analysis is valid for this structure, meaning that the complex predicate requires three functions. While this assumption is possible in our syntactic analysis, further examination may be needed in the semantic analysis, which is outside of the scope of this paper. We suggest that the complex predicate took.hit requires a subject, an object, and an indirect object. The following f-structure shows the analysis of the example in (31a):

$$
\text { (33) }\left[\begin{array}{lll}
\text { PRED } & \text { 'TAKE.HIT }\langle\text { SUBJ, OBJ, OBJ goal }\rangle \\
\text { TENSE } & \text { PAST } & \\
\text { SUBJ } & {[\text { PRED }} & \text { 'MUHAMMAD' } \\
\text { OBL } & {[\text { PRED }} & \text { 'THE STICK'] } \\
\text { OBJ goal } & {[\text { PRED }} & \text { 'THE THIEF'] }
\end{array}\right]
$$


In this f-structure, the main predicate is the complex predicate that contains the two verbs: take and hit. We assume that this complex predicate requires three functions: SUBJ, OBJ and OBJ goalWe suggest a semantic role for the indirect object, which is goal. The three functions are shown in the three embedded f-structures, where the subject is Muhammad, the object is the stick, and the indirect object is the thief.

\section{Conclusion}

This paper discussed serial verbs in MSA, arguing that this construction does exist in MSA. We examined two kinds of structures that are similar to serial verbs in MSA: the first was the being verb or kān and its sisters, which contains two verbs; here, we argue that they are not serial verbs because the two verbs occur in two clauses. The second structure is called albadal 'apposition' in traditional grammar. We argue that this structure should be analyzed as a serial verb construction based on the evidence presented. First, verbs in this structure constitute a complex situation. Second, this structure has the same tense and aspect and verbs in this structure cannot contribute different tenses or aspects. Third, verbs in this structure occur in one single clause, proven by the way both verbs must be negated or asserted together and how a pronoun cannot occur with its antecedent in this clause. Fourth, verbs in this structure must share at least one argument, which is the subject, and can also share the object. Finally, this paper discussed the syntactic analysis of serial verbs in MSA, showing that verbs in this structure should be analyzed as complex predicates.

\section{References}

1. Aikhenvald, A. Y. (2006). Serial verb constructions in typological perspective. Serial verb con- structions: $A$ cross-linguistic typology 1, 68.

2. Aikhenvald, A. Y. \& R. M. Dixon, et al. (2006). Serial verb constructions: a cross-linguistic typology (explorations in linguistic typology, vol. 2). Alandalusi (N.D.). sharh altashyl. daar hajur.

3. Alotaibi, Y. H. (2017). The analysis of auxiliaries in modern standard arabic. Journal of Faculty of Languages and Translation, 12(2).

4. Altakhaineh, A. R. M. \& A. Zibin (2018). Verb+ verb compound and serial verb construction in jordanian arabic (ja) and english. Lingua, 201: 45-56. https://doi.org/10.1016/j.lingua.2017.08.010

5. Baker, M. (1985). The mirror principle and morphosyntactic explanation. Linguisticinquiry, 16(3): 373-415.

6. Baker, M. C. (1989). Object sharing and projection in serial verb constructions. Linguistic in- quiry, 20(4), 513-553.

7. Bisang, W. (1992). Das Verb im Chinesischen, Hmong, Vietnamesischen, Thai und Khmer: ver-gleichende grammatik im rahmen der verbserialisierung, der grammatikalisierung und der at- traktorpositionen, Volume 7. Gunter Narr Verlag.

8. Bodomo, A. B. (1996). Complex predicates: The case of serial verbs in dagaare and akan. In Proceedings of the First LFG Conference, pp. 89-103.

9. Bruce, L. (1988). Serialization: from syntax to lexicon. Studies in Language. International Journal sponsored by the Foundation "Foundations of Language", 12(1): 19-49.

10. Butt, M. (1996). The Structure of Complex Predicates in Urdu. Dissertations in Linguistics. Stanford, CA. Revised and corrected version of 1993 Stanford University dissertation.

11. Byrne, F. (1987). Grammatical relations in a radical creole: Verb complementation in Saramac- can, Volume 3. John Benjamins Publishing.

12. Byrne, F. (1990). Tense marking in serial structures.

13. Chomsky, N. (1955). The Logical Structure of Linguistic Theory. New York: Plenum Press. Published in 1975.

14. Collins, C. (1997). Argument sharing in serial verb constructions. Linguistic inquiry, 461-497.

15. Crowley, T. (2002). Serial verbs in Oceanic: A descriptive typology. Oxford University Press on Demand.

16. Durie, M. (1997). Grammatical structures in verb serialization. Complex predicates 289, 354.

17. Falk, Y. N. (1984). The English Auxiliary System: A Lexical-Functional Analysis. Lan-guage 60(3), 483-509.

18. Falk, Y. N. (2008). Functional relations in the English auxiliary system. Linguistics 46/4, 861-889. https://doi.org/10.1515/ling.2008.028

19. Foley, W. A. (2010). Events and serial verb constructions. Complex predicates: Cross-linguistic perspectives on event structure, 79-109. 
20. Hyman, L. M. (1975). On the change from sov to svo: evidence from niger-congo.

21. Larson, R. (1991). Some issues in verb serialization. Serial verbs: Grammatical, comparative and cognitive approaches, 185-210.

22. Lord, C. (1993). Historical change in serial verb constructions, Volume 26. John Benjamins Publishing.

23. Ross, J. R. (1967). Constraints on variables in syntax.

24. Ross, J. R. (1986). Infinite syntax. Ablex Publishing Corporation.

25. Ryding, K. (2005). A reference grammar of modern standard Arabic. Cambridge Univ Pr.

26. Schachter, P. (1974). A non-transformational account of serial verbs. Studies in African Linguis- tics 5, 253270.

27. Schiller, E. (1990). On the definition and distribution of serial verb constructions.

28. Sebba, M. (1987). The syntax of serial verbs: An investigation into serialisation in Sranan and other languages, Volume 2. John Benjamins Publishing.

29. Seuren, P. A. (1990). Serial verb constructions. Sibawayh (N.D.). alkitaab. dar almarifah.

30. Stahlke, H. (1970). Serial verbs. Studies in African linguistics, 1(1): 60-99.

31. Stewart, J. M. (1963). Some restrictions on objects in twi. Journal of African Languages, 2(2): 145-149.

32. Van Staden, M. \& G. Reesink, et al. (2008). Serial verb constructions in a linguistic area. 